\author{
Ärztliche Erfahrung beschränkt sich nicht auf medizinisches Fachwissen. \\ Sie entsteht auch aus den mehr oder minder alltäglichen, heiter, \\ ärgerlich oder nachdenklich stimmenden Erlebnissen mit Patienten, \\ Kollegen und Mitarbeitern. Senden Sie uns Ihre Geschichte an: \\ cornelius.heyer@springer.com.
}

\title{
Unbelehrbare Naschkatzen will ich in meiner Praxis nicht
}

\begin{abstract}
Die Patientin kam von etwas weiter her, weil sie mich irgendwo in den Medien aufgetan hatte. Bei ihrer Terminvereinbarung wurden meine Damen schon stutzig, weil sie so begeistert von mir schwärmte. Nicht, dass sie mich nicht für eine gute Ärztin hielten, aber solche Lobeshymnen (und das im Voraus, ohne
\end{abstract}

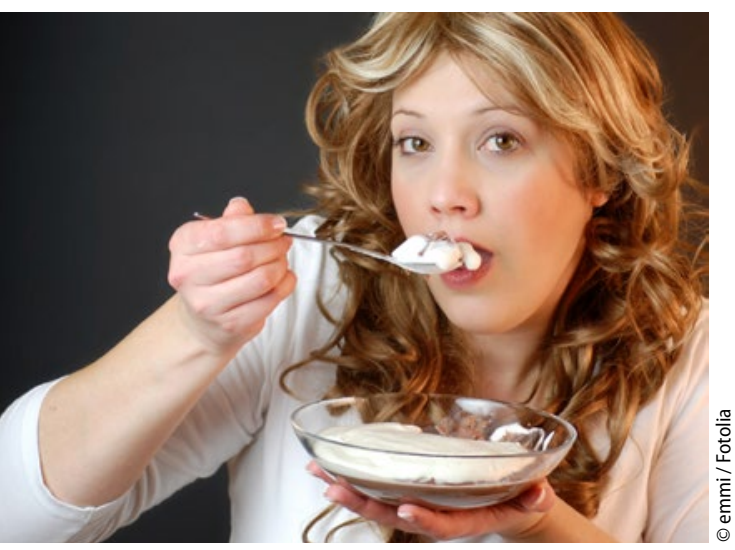

Wer so leben will, sollte nicht auch noch Vorbehalte gegen Arzneimittel haben. dass wir uns schon kennengelernt hätten) waren ihnen zu Recht suspekt. Mir auch, denn ich weiß, dass ich solch hochgesteckten Erwartungen auf Dauer kaum entsprechen kann.

Nun war sie da, und es wurde so schwierig, wie wir befürchtet hatten. Sie schleppte ein riesiges Bündel psychosomatischer Last mit sich und hatte für alles und jedes Erklärungen parat, an denen sie auch nicht rütteln wollte. Alle anderen Ärzte hatten sie bitter enttäuscht. Nein, sie wisse zwar, dass sie ihren ungesunden Lebensstil ändern müsse, aber das könne sie nicht, sagte sie. Schließlich habe sie viel zu viel Stress dafür.

Eine gründliche Untersuchung hätte sie vor Jahren mal gemacht; der ,irre hohe " Cholesterinspiegel damals hätte an ihrer Nascherei gelegen, die sie aber nicht ändern wolle, schließlich brauche sie all das Süße. Medikamente nähme sie generell nicht, denn man wisse ja, dass diese nicht gesund seien.
Ich erklärte ihr freundlich aber fest, dass ich zwar manchmal ganz nett bin, aber nicht daran dächte, meine Zeit jemandem zu widmen, der so gar nicht zur Mitarbeit bereit wäre. Meine Kraft wäre mir zu schade dafür, um mich über schlechte Stoffwechselwerte zu ärgern, die ich nur dokumentieren, aber nicht korrigieren dürfe, weil weder gesunde Ernährung noch Medikamente akzeptiert würden. Dann bat ich sie, sich einen anderen Hausarzt zu suchen. Sie war noch sprachlos, als sie aus der Tür ging.

Warum war ich so kompromisslos? Weil sie nicht die erste war, mit der mir das passiert ist! Für meine eigene gute Stimmung habe ich mir versprochen, nichts Hoffnungsloses mehr zu beginnen, das mir die Kraft raubt. Die brauche ich für Patienten, die sich wenigstens ein Minimum an Mühe geben.

Dr. Frauke Höllering, Arnsberg

\section{Kennen Sie die Restlaufzeit Ihres Partners?}

_ In verschiedenen Lebensabschnitten wird man von außen in Strukturen gezwungen. In der Jugend etwa wurden wir zum Militär eingezogen. Im Ruhestand ist es der Haushalt mit der üblichen Hausarbeit. Arbeitgeber ist dann die GEMA („Gehma eben hierhin, gehma eben dort hin“).

Anlässlich einer Arbeitsteilung beim Einkaufen hatten meine Frau und ich vereinbart, uns zu einem bestimmten Zeitpunkt wieder zu treffen, was allerdings nicht gelingen konnte, da wir beide unterschiedliche Treffpunkte im Sinn hatten. So wartete jeder von uns beiden geduldig auf den anderen. Als meine Frau schließlich am Ende ihrer Geduld angelangt war, bat sie eine neben sich sitzende Dame gleichen Alters, ob sie kurzfristig auf ihre schwere Einkaufstasche aufpassen könne. „Ich muss nach meinem Mann suchen“, war die Erklärung. Die andere Frau entgegnete nur lapidar: „Lohnt sich denn das noch?"

$\mathrm{Zu}$ meinem Leidwesen ist nicht überliefert, ob es daraufhin zu einem flammenden Plädoyer zu meinen Gunsten gekommen ist.

Dr. Udo Fuchs, Hamburg 